\title{
触 New Disease Reports \\ Association of Pigeon pea witches' broom phytoplasma (16Sr IX) infecting Phlox drummondii in India
}

\author{
Madhupriya $^{1}$, G.P. Rao ${ }^{1 *}$ and S.M.P. Khurana ${ }^{2}$ \\ ${ }^{1}$ Division of Plant Pathology, Indian Agricultural Research institute, New Delhi 110012, India; ${ }^{2}$ Amity Institute of \\ Biotechnology, Amity University Haryana 122413, India
}

*E-mail: gprao_gor@rediffmail.com

Received: 17 Jan 2013. Published: 18 May 2013.

Phlox is a genus of 67 species of perennial and annual plants in the family Polemoniaceae. Phlox are popular ornamental plants, and traditionally used to treat aches, colds, anaemia, diarrhoea and eczema. During a survey at the Indian Agricultural Research Institute Campus, New Delhi, from 2010 to 2011, symptoms including extensive yellowing and stunting, proliferation of shoots, little leaves and reduced size of flowers were observed in approximately 17\% of plants of Phlox drummondii (Fig. 1). To investigate the possibility of a phytoplasma association with the symptoms, total DNA was isolated from leaf midribs and stems of three different infected plants. Healthy-looking plants without symptoms were also collected to use as a negative control using the phytoplasma enrichment procedure (Ahrens \& Seemüller, 1992). The DNA isolated from periwinkle infected with toria phyllody phytoplasma (group 16SrIX, pigeon pea witches' broom phytoplasma; Azadvar et al., 2009) and maintained in greenhouse was used as positive control. Total DNA was used as a template for nested PCR using universal primers that target the phytoplasma 16S rRNA gene: P1/P7 (Deng \& Hiruki, 1991; Schneider et al., 1995) and R16F2n/R16R2 (Gundersen \& Lee, 1996). Expected size amplicons of $\sim 1.8 \mathrm{~kb}$ and $\sim 1.2 \mathrm{~kb}$, respectively, were amplified from al the three symptomatic $P$. drummondii plants (Fig. 2). However, no PCR products were obtained from the healthy-looking plant samples.

The amplicon of $\sim 1.2 \mathrm{~kb}$ was sequenced from a representative sample, and the consensus sequence obtained was submitted to GenBank (Accession No. KC178678). BLAST analysis of the partial 16S rDNA sequence of the $P$. drummondii phytoplasma revealed the highest sequence identity (99\%) with that of phytoplasma members of group 16SrIX, 'Candidatus Phytoplasma phoenicium', the former Pigeon pea witches' broom group. Phylogenetic analysis (MEGA version 4.0, USA) confirmed the closest phylogenetic relationship of the $P$. drummondii phytoplasma 16S rDNA sequence with those of the 16SrIX phytoplasma group (Fig. 3). Hence, the $P$. drummondii phytoplasma was identified as a 16SrIX isolate. Phytoplasmas of group 16SrI 'Candidatus Phytoplasma asteris' subgroup M (16SrI-M) have been previously associated with $P$. drummondii in Lithuania (Samuitiene et al., 2007). However, this is the first world report of the association of the 16SrIX group with a phytoplasma disease on $P$. drummondii.

\section{Acknowledgements}

The first author is thankful to Department of Science and Technology, New Delhi, India for providing financial assistance under WOS 'A' scheme. The authors wish to express sincere thanks to Head, Division of Plant Pathology and Director, Indian Agricultural Research Institute for providing laboratory facilities.

\section{References}

Ahrens U, Seemüller E, 1992. Detection of DNA of plant pathogenic mycoplasma-like organisms by a polymerase chain reaction that amplifies a sequence of the 16S rRNA gene. Phytopathology 82, 828-832. [http://dx.doi.org/10.1094/Phyto-82-828]

Azadvar M, Baranwal VK, Yadava DK, 2009. First report of a 16SrIX (Pigeon pea witches' broom) phytoplasma associated with toria (Brassica rapa cv. toria) phyllody disease in India. New Disease Reports 20, 27.

Deng S, Hiruki C, 1991. Amplification of 16 S rRNA genes from culturable and non-culturable mollicutes. Journal of Microbiological Methods 14, 53-61. [http://dx.doi.org/10.1016/0167-7012(91)90007-D]

Gundersen DE, Lee IM, 1996. Ultrasensitive detection of phytoplasmas by nested-PCR assays using two universal primer sets. Phytopathologia Mediterranea 35, 144-151.

Schneider B, Seemüeller E, Smart CD, Kirkpatrick BC, 1995. Phylogenetic classification of plant pathogenic mycoplasma-like organisms or phytoplasmas. In: Razin S, Tully JG eds. Molecular and Diagnostic Procedures in Mycoplasmology. San Diego, CA, USA: Academic Press, 369-380.

Samuitienė M, Jomantienė R, Valiūnas D, Navalinskienė M, Davis RE, 2007. Phytoplasma strains detected in ornamental plants in Lithuania. Bulletin of Insectology 60, 137-138.

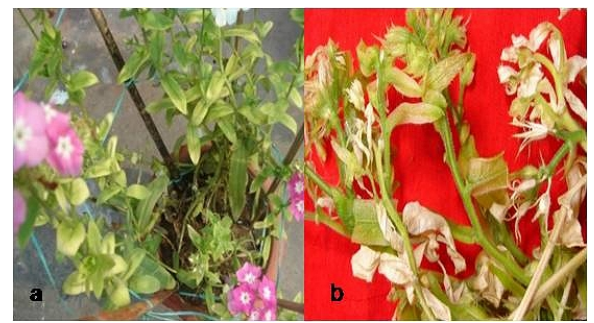

Figure 1

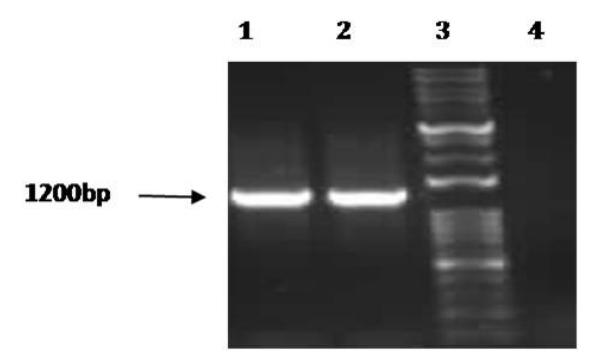

Figure 2

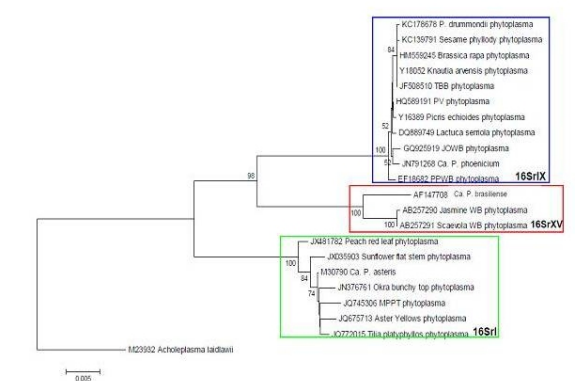

Figure 3

To cite this report: Madhupriya, Rao GP, Khurana SMP, 2013. Association of Pigeon pea witches' broom phytoplasma (16Sr IX) infecting Phlox drummondii in India. New Disease Reports 27, 15. [http://dx.doi.org/10.5197/j.2044-0588.2013.027.015] 